\title{
Influência dos Valores Laborais dos Pais sobre os Valores Laborais dos Filhos
}

\author{
Parents Work Values Influence on Sons Work Values \\ Juliana Barreiros Porto ${ }^{\mathrm{a} *}$, \& Alvaro Tamayo ${ }^{\mathrm{b}}$ \\ ${ }^{a}$ Universidade Presbiteriana Mackenzie / Instituto de Ciências do Trabalho \\ ${ }^{\mathrm{b}}$ Universidade de Brasília / Universidade Católica de Brasília
}

\begin{abstract}
Resumo
Valores laborais são princípios ou metas, hierarquicamente organizadas, que as pessoas buscam e que guiam a sua vida no trabalho. A família, a escola e a experiência de trabalho são apontadas como as variáveis mais influentes na formação dos valores laborais. Os pais são considerados os agentes socializadores mais influentes nesse processo, pois servem como modelo de trabalhador para as crianças. O objetivo do presente trabalho é investigar a influência dos valores paterno e materno nos valores laborais de estudantes universitários. Participaram 129 estudantes universitários, de 17 cursos escolhidos aleatoriamente, seus pais (84 mães e 45 pais) e 956 colegas de curso dos estudantes. Os participantes responderam à Escala de Valores Relativos ao Trabalho. Os resultados das regressões hierárquicas indicaram que os pais e os colegas exercem influência sobre os valores laborais de Realização Profissional e Estabilidade dos estudantes. São discutidas a relevância e as limitações desses resultados no artigo.

Palavras-chave: Valores do trabalho; formação de valores; valores pessoais.
\end{abstract}

\begin{abstract}
Work values are principles or goals, ordered by importance, that people seek and that guide his/her life at work. Family, school and work experiences are indicated as the most important factors in the formation of work values. Parents are considered the most influential social agent in this process, since they serve as a role model to their children. The present study examines the impact of the work values of parents on the work values of college students. One hundred and twenty nine (129) students and their parents (84 mothers and 45 fathers) in 17 randomly chosen undergraduate courses, as well as 956 colleagues of these students participated in this investigation. They answered the Work Values Scale. The results of the hierarchical regressions demonstrated that parents and colleagues influence the student's work values of Professional Achievement and Stability. The relevance and limitations of these results are discussed in this paper.

Keywords: Work values; values development; personal values.
\end{abstract}

Os valores têm sido estudados por várias áreas do conhecimento humano para predizer atitudes e comportamentos das pessoas e para justificar o curso das ações tomadas. Allport foi um dos precursores no estudo de valores, porém, como afirma Rohan (2000, p.255), "o seu entusiasmo pelo construto perdeu influência com o crescimento do behaviorismo". Posteriormente, Rokeach (1973) retorna a este tema e desenvolve um trabalho que é referência para os estudiosos de valores. Recentemente, o interesse pelos valores cresceu de forma acentuada, especialmente com o início de pesquisas transculturais. No Brasil, Biaggio e Camino (Biaggio, 1999; Camino, 2003; Camino, Camino, \& Moraes, 2003) têm contribuído com o estudo dos valores morais e societais enfatizando a sua importância no julgamento moral e a sua relação com as

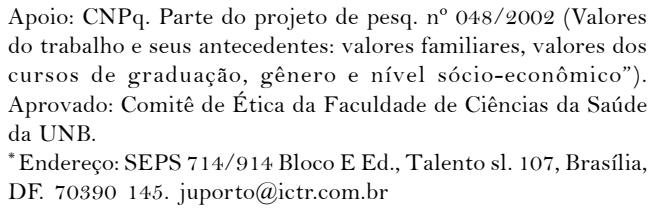
do trabalho e seus antecedentes: valores familiares, valores dos cursos de graduação, gênero e nível sócio-econômico"). Aprovado: Comitê de Ética da Faculdade de Ciências da Saúde da UNB.

*Endereço: SEPS 714/914 Bloco E Ed., Talento sl. 107, Brasília, DF.70390 145. juporto@ictr.com.br

ideologias políticas e sócio-econômicas. Entretanto, alguns problemas afetaram o desenvolvimento da área de valores. Rohan (2000) afirma que a palavra 'valores' é objeto de abusos por psicólogos e não psicólogos o que também prejudica os estudos sobre valores ao gerar confusão sobre sua definição. Além disso, o estudo dos valores pode ser feito em diferentes níveis, visto que os sistemas sociais são compostos por múltiplos níveis como sociedade, grupos e indivíduos. Assim, a definição do conceito assume grande relevância aliada à necessidade de identificação do nível de análise.

As teorias mais recentes sobre valores trabalham com dois níveis: o individual e o cultural. Os valores individuais são estruturas cognitivas intrapsíquicas e podem ser pessoais e sociais. Os valores pessoais se referem a princípios que guiam a vida do indivíduo e os sociais, à percepção do indivíduo sobre os princípios defendidos pelo grupo. Os valores culturais, por sua vez, servem para estabelecer crenças compartilhadas que definem que tipo de comportamento é apropriado nas diversas situações, além de servir para justificar o motivo daquela escolha (Schwartz \& Ros, 1995). 
O foco do presente estudo são os valores pessoais, especialmente os valores laborais. Os valores são definidos por Schwartz (1999) como critérios ou metas que transcendem situações específicas, que são ordenados por sua importância e que servem como princípios que guiam a vida do indivíduo. Para ele os valores são indicadores importantes das motivações da pessoa. As pessoas apresentam uma estrutura de valores que guia a sua vida de maneira geral. Essa estrutura é ampla e inclusiva. Para cada aspecto da vida como, p. ex., o trabalho, a religião, o esporte e a política, as pessoas apresentam uma estrutura de valores específica que está relacionada com aquela estrutura mais abrangente (Sagie \& Elizur, 1996).

Valores estão relacionados tanto com a escolha vocacional (Dawis, 1992; Judge \& Bretz, 1992; Roe \& Ester, 1999) quanto com a predição de atitudes e comportamentos no ambiente de trabalho, como comprometimento organizacional (Meyer, Irving, \& Allen, 1998; Sagie \& Elizur, 1996), satisfação no trabalho (Cheung \& Scherling, 1999; Taris \& Feij, 2001) e desempenho (Sagie \& Elizur, 1996). Outra linha de estudo que tem crescido é a das diferenças dos valores laborais entre culturas (Borg \& Braun, 1996; Elizur, Borg, Hunt, \& Beck, 1991; Schwartz, 1999; Sidani \& Gardner, 2000; Sverko, 1999). O interesse por esta última linha parece ter como impulsionador a inserção de um maior número de empresas em países estrangeiros e o processo de aculturação das empresas. O conhecimento dos valores laborais nas diversas culturas seria um facilitador desses processos. No entanto, os processos de transmissão dos valores laborais e a influência dos pais sobre os filhos são pouco explorados na literatura.

Assim, o presente trabalho busca contribuir para diminuir essa lacuna ao investigar a influência dos valores laborais de pais, controlado o efeito do gênero, experiência de trabalho, gênero dos pais e valores dos colegas de curso, sobre os valores laborais dos estudantes universitários.

Valores laborais são princípios ou metas, hierarquicamente organizadas, que as pessoas buscam e que guiam a sua vida no trabalho (Porto \& Tamayo, 2003). Essa definição apresenta três aspectos relevantes para a especificação do conceito: a) Cognitivo - os valores laborais são crenças sobre o que é ou não desejável no trabalho; b) Motivacional expressam interesses e desejos do indivíduo em relação ao seu trabalho; e, c) Hierárquico - são avaliados ao longo de um continuum de importância. A teoria utilizada fundamenta-se na teoria de Ros, Schwartz, e Surkiss (1999). Esses autores revisaram as estruturas sobre valores laborais presentes na literatura e sugeriram um modelo que se baseia na Teoria de Schwartz dos Valores Pessoais.

Segundo a teoria de Schwartz (1992), pode-se identificar quatro tipos motivacionais de segunda ordem nos valores pessoais: Autotranscedência, Autopromoção, Abertura à Mudança e Conservadorismo. Considerando os valores laborais como expressão dos valores gerais no ambiente de trabalho, pode-se supor que os quatros tipos motivacionais propostos na teoria dos valores gerais podem ser encontrados para os valores laborais. Ros et al. (1999) propuseram e testaram um modelo composto por 4 tipos motivacionais: 1 )
Valores intrínsecos que estariam associados à Abertura à Mudança; 2) Valores extrínsecos ou materiais associados a Conservadorismo; 3) Valores sociais ou afetivos associados à Autotranscendência; e 4) Poder associado à Autopromoção. Da mesma forma que nos valores gerais, foi encontrada a dinâmica de compatibilidade e conflito entre os valores laborais, ou seja, os quatro tipos motivacionais formaram pólos opostos de duas dimensões. Assim, Valores sociais se opõem a Autopromoção e Valores intrínsecos se opõem a Valores extrínsecos.

Com base nesse modelo, Porto e Tamayo (2003) desenvolveram e validaram uma escala de valores laborais no Brasil. Os resultados da análise fatorial indicaram os mesmos quatro fatores encontrados por Ros et al. (1999) e foram assim denominados:

1- Realização Profissional: refere-se à busca de prazer e realização pessoal e profissional, bem como de independência de pensamento e ação no trabalho por meio da autonomia intelectual e da criatividade;

2- Estabilidade: refere-se à busca de segurança e ordem na vida por meio do trabalho, possibilitando suprir materialmente as necessidades pessoais;

3- Relações Sociais: refere-se à busca de relações sociais positivas e de contribuição positiva para a sociedade por meio do trabalho;

4- Prestígio: refere-se à busca de autoridade, sucesso profissional e poder de influência no trabalho.

A transmissão de valores é um processo necessário para a formação dos valores do indivíduo e para a socialização dos membros do grupo social. Do ponto de vista evolucionista, a cultura foi um processo desenvolvido pelo homem que propiciou uma adaptação mais eficiente a ambientes mutáveis e foi transmitido de geração em geração através da aprendizagem. Assim, a cultura permite uma adaptação mais rápida ao ambiente, em contraposição ao desenvolvimento de genes específicos para cada necessidade. Cavalli-Sforza (1993) afirma:

Ser capaz de aprender por meio de um mecanismo geral e transmitir as habilidades necessárias para a sobrevivência da prole e de outros membros do grupo, possibilitou a ocupação de novos nichos ambientais com maior rapidez do que desenvolvendo adaptações genéticas específicas. (p.314)

Apesar desse aspecto positivo, ele afirma que a transmissão cultural falha e deve haver considerável interação entre adaptação genética e cultural. Da mesma forma, o significado adaptativo dos valores é que eles favorecem o aparecimento de comportamentos adaptativos a ambientes variáveis, aumentam a flexibilidade do indivíduo para enfrentar ambientes novos, sem a necessidade de especificar uma resposta comportamental para cada situação. A capacidade do ser humano de avaliar o contex to no qual está inserido e escolher aqueles valores que são mais adaptativos foi extremamente importante para sua sobrevivência. Michod (1993) afirma que "a evolução nos proporcionou os valores ao invés de nos programar geneticamente” (p.268). 
O processo de transmissão envolve a transferência de informação entre indivíduos e grupos e é responsável pela similaridade encontrada, por exemplo, entre pais e filhos e entre grupos que convivem no mesmo ambiente. Segundo Cavalli-Sforza e Feldman (citado em Schönpflug, 2001a), a transmissão genética é uma das fontes responsáveis pela similaridade entre pais e filhos, entretanto a semelhança nas orientações sociais, habilidades e conhecimento acumulado não deve estar relacionada aos genes e devem ser analisadas outras formas de transmissão como a cultural. A transmissão cultural é definida por Cavalli-Sforza (1993) como o resultado da transmissão via comunicação por outros indivíduos, seja por meio da observação, imitação, condicionamento ou educação.

A transmissão cultural de valores requer alguma forma de aprendizagem social em oposição à transmissão genética e não reproduz exatamente a cultura anterior (Schönpflug, 2001 b). O processo de transmissão cultural deve se adequar ao meio externo para se tornar adaptativo, pois tanto a transmissão total quanto a falha na transmissão são problemáticas para a sociedade. A primeira porque impede a flexibilidade para se adaptar ao novo ambiente e a segunda porque não permite a coordenação de ações entre uma geração e outra (Schönpflug, 2001b).

Vários são os transmissores de cultura em uma sociedade: os pais, os professores, os amigos, a religião, a mídia, entre outros. Segundo Schönpflug (2001a, 2001b), a transmissão cultural intergeracional ou vertical é um conceito apropriado quando o adulto intencionalmente ensina ao jovem ou quando o jovem imita o adulto.

Os pesquisadores na área de valores têm concentrado seus esforços no estudo da transmissão cultural, especificamente, a vertical. A maioria desses estudos investigou a transmissão dos valores gerais. Os autores que têm buscado comprender a transmissão cultural têm realizado pesquisas considerando ora o resultado da transmissão ora os processos. Os estudos sobre os resultados investigam a semelhança de valores entre grupos ou a influência de um grupo sobre outro. Já os estudos sobre processos de transmissão têm o objetivo de averiguar os mecanismos e variáveis envolvidas na maior ou menor efetividade da transmissão cultural. O presente estudo está dentro da primeira linha e o termo influência dos valores de um indivíduo sobre outro será utilizado como equivalente a transmissão.

Wijting, Arnold, e Wijting. (1978) enfatizam que os valores laborais são desenvolvidos por meio da interação e da identificação com vários agentes socializadores, como também, por meio das experiências dos indivíduos na família, na escola e no ambiente de trabalho. O agente socializador primário e potencialmente mais influente, pelo menos durante o início e meio do desenvolvimento vocacional, são os pais. Eles são o principal modelo de trabalhador para as crianças. Apesar da relevância da família para a formação dos valores laborais, poucos são os estudos que investigaram essa relação.

Wijting et al. (1978) buscaram acessar a diferença de papéis entre pais e mães na transmissão dos valores laborais para as crianças, por meio da comparação entre os valores laborais de pais e mães e seus filhos e filhas em quatro anos escolares. O estudo também comparou os valores laborais de meninos e meninas entre si e através dos anos escolares, para examinar a estabilidade dos padrões de valores laborais do sexto ao décimo segundo ano de escola. Os resultados confirmam a hipótese de que os valores laborais das crianças mais novas são mais similares aos de seus pais do mesmo sexo e de que os valores laborais das crianças mais velhas são mais parecidos com os dos seus pais de sexo masculino.

As formas como os valores são transmitidos foram estudadas por Iversen, e Farber (1996). Foram executadas entrevistas intensivas sobre a história de vida de 50 mulheres negras com idade entre 13 e 23 anos nos Estados Unidos. Os autores detectaram três processos centrais de transmissão de valores. São eles: a) Mensagens diretas verbais: referem-se a comunicações verbais positivas ou negativas sobre o trabalho, repetidas freqüentemente; b) Ações tangíveis: referem-se a ações direcionadas a ajudar os adolescentes nos seus esforços em relação a educação e trabalho; e, c) Exemplos/Mensagens indiretas: Referem-se aos exemplos de trabalho e histórico profissional dos pais ou membros da família.

Não foram encontradas outras pesquisas que tenham investigado a relação entre valores laborais e a influência dos pais. Entretanto, na área de valores gerais, tem crescido o interesse pela transmissão dos valores de pais para filhos, especialmente para compreender os processos de aculturação em famílias de imigrantes. Os resultados encontrados nessa área podem ser úteis para compreender a transmissão dos valores laborais.

Rohan e Zanna (1996) realizaram um estudo para investigar a similaridade de valores entre pais e filhos e os fatores que influenciariam tal similaridade. Participaram do estudo 71 estudantes universitários do sexo masculino e seus pais (50 mães e 46 pais). Os pesquisadores utilizaram como medida de valores o Inventário de Valores de Schwartz (1992). Os resultados apontaram que a similaridade de valores entre pais e filhos é moderada pelo nível de autoritarismo e responsividade dos pais. Pais com alto grau de autoritarismo (definido pela escala de Altemeyer, citado em Rohan \& Zanna, 1996) têm probabilidade menor de ter filhos com valores similares aos seus. Os autores descobriram ainda que essa relação é mediada pela percepção do filho sobre o estilo parental responsivo.

Schönpflug (2001b) investigou a influência dos valores dos pais sobre os valores dos filhos. Uma amostra composta por 300 adolescentes entre 14 e 19 anos e um dos seus pais respondeu ao Inventário de Valores de Schwartz. Além disso, os filhos responderam a escalas sobre percepção de estilos parentais e os pais a uma escala de atitudes em relação ao casamento. $\mathrm{O}$ autor esperava encontrar maiores diferenças geracionais em contextos descontínuos, pois os pais estariam menos motivados a transmitir os seus padrões e atitudes à geração seguinte sob o pressuposto que esses não são adaptativos para o futuro dos seus filhos. Outra hipótese aventada era a de que os valores coletivistas seriam 
privilegiados na transmissão por incentivarem os valores do grupo. Entretanto os resultados encontrados não confirmaram essas hipóteses. Os resultados apontaram que: 1) a diferença geracional dos valores não foi maior para contextos culturais descontínuos em comparação com contextos contínuos; 2) valores coletivistas sofreram transmissão vertical, enquanto os individualistas não, exceto os valores de autodeterminação; 3) a intensidade da transmissão foi moderada pelo estilo parental e pela atitude frente ao casamento; e, 4) a transmissão foi mais prevalente para os filhos posteriores ao primogênito que para este. Schönpflug conclui que a transmissão de valores serve também a interesses individuais e que os pais devem ter competências no uso de estratégias para convencer os filhos a internalizar certos valores. Uma dessas competências seria o uso de estilo parental empático. O estudo aponta ainda para maior semelhança de valores entre pais e filhos nos estágios iniciais e medianos da adolescência do que no final. Sendo que os valores coletivistas são transmitidos na primeira metade da adolescência e a importância de uma vida estimulante, mais tardiamente.

Dentro da perspectiva do desenvolvimento moral de Kohlberg, Biaggio desenvolveu uma série de pesquisas sobre os fatores intrínsecos e extrínsecos que afetam o desenvolvimento moral. Destaca-se uma pesquisa realizada em 1979 em que ela detectou que a influência dos colegas é mais forte do que as influências maternas no desenvolvimento moral de adolescentes brasileiros. Além disso, os resultados apontaram que as atitudes de severidade e de desligamento hostil da mãe afetam negativamente o desenvolvimento moral (Camino, 2003).

Em resumo, as pesquisas apresentadas acima apontam para a transmissão vertical dos valores e também indicam que o aumento da idade enfraquece a similaridade entre pais e filhos, pois outros agentes socializadores passam a exercer maior influência.

Desta forma, o objetivo deste estudo foi o de investigar a influência dos valores laborais de pais, controlado o efeito do gênero, experiência de trabalho, gênero dos pais e valores dos colegas de curso, sobre os valores laborais dos estudantes universitários. A seguir apresenta-se a metodologia e os resultados encontrados.

\section{Método}

\section{Amostra}

Participaram deste estudo 129 estudantes universitários e seus pais (84 mães e 45 pais) de 17 cursos universitários escolhidos aleatoriamente. Além dos pais e dos estudantes, participaram 956 colegas de curso, entendidos aqui como os estudantes do curso que estivessem no mesmo período de curso do estudante-alvo.

Dos estudantes-alvo, $58 \%$ eram do sexo feminino, $94 \%$ eram solteiros, $78 \%$ residiam com os pais, $52 \%$ tinham experiência de trabalho, $39 \%$ eram católicos e a média de idade era de 21 anos $(d p=4,12)$. Dos pais, $65 \%$ eram do sexo feminino, $67 \%$ eram católicos, $70 \%$ eram casados, $23 \%$ eram solteiros e $51 \%$ tinham curso superior completo. Dos colegas de curso, $52 \%$ eram do sexo feminino, $92 \%$ eram solteiros, $76 \%$ residiam com os pais, $57 \%$ tinham experiência de trabalho, $45 \%$ eram católicos e a média de idade foi de 21 $\operatorname{anos}(d p=4,11)$.

\section{Instrumento}

Para avaliar os valores laborais dos estudantes universitários, dos pais e dos colegas de curso foi utilizada a Escala de Valores relativos ao Trabalho (EVT) desenvolvida e validada por Porto e Tamayo (2003). A escala é composta por 32 itens divididos em quatro fatores: Realização Profissional (alpha $=0,87$ ), Estabilidade (alpha=0,86), Prestígio (alpha $=0,85$ ) e Relações Sociais (alpha $=0,84$ ). Além da EVT, os participantes ainda responderam a perguntas sobre dados pessoais.

\section{Procedimento}

Para a coleta de dados, os cursos foram escolhidos aleatoriamente e os alunos que se encontravam em sala de aula no dia da aplicação foram convidados a participar da pesquisa. Todos os alunos foram informados sobre os objetivos da pesquisa e apenas os que consentiram em participar responderam ao questionário.

Os estudantes universitários responderam ao questionário em sala de aula, enquanto que os pais responderam via correio eletrônico ou postal. No total 1.083 estudantes responderam ao questionário, para 465 foi solicitado o endereço do pai e para 459 o endereço da mãe. Destes, 727 consentiram em apresentar o endereço dos seus pais para que fosse encaminhado um questionário a eles. Dos 727 questionários, 299 apresentaram o correio eletrônico dos seus pais. Inicialmente, foi encaminhado o questionário por correio eletrônico. Após esse envio, foi realizado o envio por correio postal para os demais e para aqueles casos em que o endereço eletrônico apresentou problema. Assim, foram encaminhados 299 questionários por correio eletrônico e 358 por cartas. Os demais dados foram perdidos por apresentarem endereços incompletos ou letra ilegível. A taxa de retorno dos questionários foi de $20 \%$.

Em relação a análise de dados, inicialmente, foi calculado um índice dos valores laborais dos colegas de curso. O índice foi composto pela média de respostas na EVT dada por todos os universitários da amostra que estavam no mesmo período de curso do estudante-alvo.

A análise de dados foi realizada utilizando regressões hierárquicas em que os quatro fatores da EVT respondidos pelos estudantes-alvo constituíam-se na VD. No primeiro bloco de variáveis independentes, foram introduzidas as variáveis demográficas (gênero, gênero do pai que respondeu ao questionário e experiência de trabalho) com o objetivo de controlar o efeito das mesmas. No segundo os valores laborais dos colegas de curso. E, no último, os valores laborais dos pais que são os principais transmissores de valores. No total foram realizadas quatro regressões hierárquicas, uma para cada fator da EVT. 


\section{Resultados e Discussão}

As correlações entre as variáveis independentes e dependentes, bem como a média e desvio-padrão das variáveis dependentes estão na Tabela 1. Os resultados das análises de regressão para os fatores Realização Profissional e Estabilidade podem ser visualizados nas Tabelas 2 e 3. Essas tabelas apresentam o R, $\mathrm{R}^{2}, \mathrm{R}^{2}$ ajustado, b e correlações para cada regressão. Os fatores Prestígio e Relações sociais não foram significativamente preditos pelas variáveis independentes.

Os preditores significativos do fator Realização Profissional foram os valores de realização profissional tanto dos pais quanto dos colegas de curso e os valores de prestígio dos pais (Tabela 1). Esse modelo explicou $24 \%$ da variância de Realização Profissional ( $\mathrm{F}=7,78, p<0,01)$. A importância dada aos valores de realização por pais e por colegas apresenta uma relação positiva com a importância dada, pelo indivíduo, a esses valores, conforme era esperado teoricamente, já que no processo de transmissão cultural os membros dos grupos sociais influenciam os demais a terem valores similares aos defendidos pelo grupo.

Da mesma forma que para o fator realização profissional, para o fator estabilidade, quanto mais os pais e os colegas valorizavam a estabilidade, mais os indivíduos valorizavam a estabilidade no trabalho (Tabela 3). Esse modelo explicou $9 \%$ da variância de Estabilidade $(\mathrm{F}=3,64, p<0,01)$. Para este fator, a relação com os valores dos colegas de curso foi mais forte do que com os dos pais. Os valores dos pais explicaram $3 \%$ da variância enquanto que ao acrescentar os valores dos colegas houve um acréscimo de $7 \%$ ao $\mathrm{R}^{2}$. É possível que fatores como o tempo de convivência na universidade, as inúmeras atividades acadêmicas que devem ser realizadas em conjunto e os próprios interesses em comum que os colegas de curso possuem favoreçam a criação de vínculos entre os estudantes. A convivência torna os colegas de curso pessoas importantes para o indivíduo e cria as condições necessárias para que ocorra transmissão de valores. Além disso, os colegas de curso fazem parte do ambiente institucionalizado e podem exercer influência sobre os valores dos estudantes sem que haja necessidade de serem pessoas significativas. $\mathrm{O}$ resultado obtido pode também ser um reflexo da fase de vida dos indivíduos que participaram da pesquisa, pois geralmente é no final do curso universitário que os jovens começam a buscar a sua independência financeira e o trabalho é visto como uma forma de alcançar essa meta. Esses resultados estão em sintonia com o trabalho de Biaggio (1979, citado por Camino, 2003) que também encontrou uma influência mais forte dos colegas do que das mães.

Tabela 1

\begin{tabular}{|c|c|c|c|c|}
\hline & Realização profissional & Estabilidade & Prestígio & Relações sociais \\
\hline Gênero & $0,29^{*}$ & 0,01 & $-0,23^{*}$ & 0,10 \\
\hline Experiência de trabalho & $-0,09$ & $-0,01$ & 0,01 & $-0,07$ \\
\hline Gênero do pai & $-0,04$ & $-0,12$ & $-0,16$ & $-0,13$ \\
\hline Realização Profissional colegas & $0,38 * *$ & 0,06 & $-0,06$ & 0,10 \\
\hline Estabilidade colegas & $-0,05$ & $0,31 * *$ & $0,31 * *$ & $-0,05$ \\
\hline Prestígio colegas & $-0,10$ & $-0,02$ & 0,16 & $-0,06$ \\
\hline Relações sociais colegas & 0,15 & $-0,01$ & $-0,12$ & 0,02 \\
\hline Realização Profissional pais & 0,12 & $-0,04$ & $-0,01$ & 0,04 \\
\hline Estabilidade pais & $-0,02$ & $-0,12$ & 0,06 & $-0,07$ \\
\hline Prestígio pais & $-0,26 *$ & 0,06 & 0,06 & $-0,03$ \\
\hline Relações sociais pais & $-0,28$ & $-0,12$ & $-0,12$ & 0,07 \\
\hline$m$ & 4,25 & 3,92 & 2,50 & 3,51 \\
\hline$d p$ & 0,59 & 0,63 & 0,75 & 0,65 \\
\hline
\end{tabular}

Tabela 2

Regressão Hierárquica dos Valores dos Pais e Colegas sobre o Fator Realização Profissional

\begin{tabular}{|c|c|c|}
\hline Variáveis & $B$ & $\beta$ \\
\hline \multicolumn{3}{|l|}{$1^{\circ}$. Bloco: Demográficas } \\
\hline Gênero & $0,26^{*}$ & 0,22 \\
\hline Experiência de trabalho & 0,08 & 0,07 \\
\hline Gênero do pai & $-0,14$ & $-0,12$ \\
\hline \multicolumn{3}{|l|}{ 2. Bloco: Valores colegas } \\
\hline Realização Profissional & $1,09 *$ & 0,29 \\
\hline \multicolumn{3}{|l|}{ 3. Bloco: Valores pais } \\
\hline Realização Profissional & $0,22 *$ & 0,22 \\
\hline Prestígio & $-0,25^{*}$ & $-0,28$ \\
\hline & \multicolumn{2}{|c|}{$\begin{array}{l}\text { Intercepto }=-1,05 \\
\mathrm{R}^{2}=0,28 \\
\mathrm{R}^{2} \text { Ajustado }=0,24 \\
\mathrm{R}=0,53^{*}\end{array}$} \\
\hline
\end{tabular}

Nota. ${ }^{*} p<0,01$

Tabela 3

Regressão Hierárquica dos Valores dos Pais e Colegas sobre o Fator Estabilidade

\begin{tabular}{|c|c|c|}
\hline Variáveis & $B$ & $\beta$ \\
\hline \multicolumn{3}{|l|}{$I^{\circ}$. Bloco: Demográficas } \\
\hline Gênero & $-0,03$ & 0,02 \\
\hline Experiência de trabalho & $-0,02$ & $-0,18$ \\
\hline Gênero do pai & $-0,13$ & $-0,09$ \\
\hline \multicolumn{3}{|l|}{$2^{\circ}$. Bloco: Valores colegas } \\
\hline Estabilidade & $0,88^{*}$ & 0,27 \\
\hline \multicolumn{3}{|l|}{ 3. Bloco: Valores pais } \\
\hline Estabilidade & $0,20^{* *}$ & 0,10 \\
\hline & \multicolumn{2}{|c|}{$\begin{array}{l}\text { Intercepto }=-0,20 \\
\mathrm{R}^{2}=0,13 \\
\mathrm{R}^{2} \text { Ajustado }=0,09 \\
\mathrm{R}=0,36^{*}\end{array}$} \\
\hline
\end{tabular}


A importância dada aos valores de prestígio pelos pais apresentou uma relação negativa com a importância dada aos valores de realização dos estudantes (Tabela 2). Era de se esperar uma relação positiva entre valores de prestígio e realização profissional, já que esses fatores apresentam correlação positiva entre si. Entretanto, na transmissão dos valores entre pais e filhos a influência dos valores de prestígio é negativa para os valores de realização profissional. Esse fato pode indicar que os filhos percebem uma relação de conflito entre a busca de prestígio e realização profissional. Assim, quando os pais valorizam mais o prestígio, os filhos tendem a dar menos importância à realização, como se alcançar as duas metas fosse tarefa incompatível. Por outro lado, os valores de prestígio dos pais e dos colegas não predisseram significativamente os valores de prestígio dos estudantes universitários, o que indica que os antecedentes desses valores podem ser outros que não a influência dos pais e dos colegas.

Para o fator relações sociais, os valores dos pais e dos colegas também não apresentaram relações significativas. A literatura aponta para diferenças de gênero no tipo motivacional Autotranscendência. Era esperado, portanto, que essa mesma diferença se reproduzisse no fator relações sociais, mas a diferença de gênero não foi significativa. $\mathrm{O}$ gênero apresentou relação significativa com os valores de realização profissional e prestígio. As mulheres apresentaram médias mais altas para realização profissional e os homens para prestígio. Diferenças de gênero para o prestígio já foram encontradas em vários outros estudos (Elizur, 1994; Harpaz, 1990; Manhardt, 1972; Mottaz, 1986; Neil \& Snizek, 1987; Sagie, Elizur, \& Koslowski, 1996) e os dados referentes a esta amostra brasileira confirmam a diferença entre homens e mulheres para o prestígio.

Com relação a diferença de gênero para o fator relações sociais, em geral as pesquisas mostram que as mulheres valorizam mais as relações sociais do que os homens. Entretanto, os dados da pesquisa não indicaram essa relação, mas sim que elas valorizam mais a realização profissional. Talvez o resultado seja função ou da influência do tipo de ocupação, ou da amostra estudada, caracterizada por estudantes universitários, que questionam fortemente os papéis de gênero.

Os resultados das pesquisas anteriores sobre a associação entre gênero e valores intrínsecos apontam que os homens valorizam mais a independência, autonomia e responsabilidade (Elizur, 1994; Harpaz, 1990) e as mulheres valorizam mais o envolvimento com a tarefa quando em ocupações de maior prestígio (Mottaz, 1986). Estes resultados são contraditórios e tornam difícil a comparação com a presente pesquisa, devido ao uso de medidas diferentes em que, muitas vezes, os valores intrínsecos englobam os fatores prestígio e realização profissional ou se relaciona gênero a valores isolados.

Os resultados obtidos pela presente pesquisa apontam claramente para diferença de gênero no fator realização profissional. As mulheres pesquisadas dão mais importância à busca de prazer e realização pessoal e profissional. Esse resultado novo na literatura pode ser um indicador de mudança cultural e está de acordo com a pesquisa de Tamayo (1998), que encontrou que as adolescentes valorizam mais a Autodeterminação que os adolescentes. Os dados aqui relatados dão mais suporte à idéia de que as mulheres buscam não somente metas alocêntricas (busca do bem-estar dos outros), mas também metas idiocêntricas (busca de sucesso pessoal). Outra possibilidade é que, no ambiente de trabalho, as mulheres buscam metas diferentes daquelas desejadas em outros contextos de sua vida, apontando para um mecanismo compensatório nas relações entre as metas buscadas nos diferentes contextos. Enquanto para guiar a sua vida de maneira geral, na família e na sociedade, as mulheres desejam alcançar metas alocêntricas, no trabalho há a busca de prazer e independência.

A educação é um recurso pessoal do transmissor, com efeito positivo sobre a transmissão. Os pais com mais educação podem encontrar maior aceitação como modelos para os seus filhos (Schönpflug, 2001b). Os pais da presente amostra possuíam na sua maioria curso superior completo o que os habilitaria a ter mais recursos e maior competência para transmitir os valores para seus filhos. Os resultados não demonstraram haver influência significativa da escolaridade dos pais sobre a transmissão dos valores, provavelmente porque a variabilidade foi pequena para esta variável. Os resultados apontam que os pais têm tido competência para transmitir os valores de realização que são apontados na literatura como os valores predominantes entre pais com maior escolaridade (Phalet \& Schönpflug, 2001).

Os resultados deste estudo estão em consonância com a pesquisa desenvolvida por Schönpflug (2001b) que identificou maior semelhança de valores entre pais e filhos nos estágios iniciais da adolescência do que no final e que valores de estimulação são transmitidos mais tardiamente. A presente amostra foi composta por jovens adultos que apresentam maior autonomia em relação aos pais e possibilita a influencia de outros transmissores dificultando assim a identificação do que foi transmitido pela família. Além disso, estes jovens encontram-se em período universitário. Nessa etapa da vida, vários valores trazidos do ambiente familiar podem ser questionados. Observa-se, todavia, uma influência relativamente forte dos pais, especialmente para valores de realização profissional, sendo que não foi encontrada influência para os valores de relações sociais.

De acordo com as teorias sociais evolucionistas (Phalet \& Schönpflug, 2001), os valores altruístas e as motivações que servem ao endo-grupo são privilegiados no processo de transmissão cultural dos valores por permitir a sobrevivência do grupo. Assim, os grupos sociais selecionam o tipo de valor que será transmitido para os seus membros, visando àqueles que são mais adaptativos. No caso dos valores gerais, os valores altruístas podem ser privilegiados, como aponta a pesquisa de Phalet e Schönpflug (2001). A presente pesquisa ressalta que para a vida no trabalho a transmissão dos valores de relações sociais, que estariam 
mais associados aos valores de autotranscendência, não são transmitidos prioritariamente, mas sim os valores de realização profissional e estabilidade. Possivelmente, estes valores são percebidos como mais importantes para garantir um comportamento mais adequado ao ambiente de trabalho, em especial para o ambiente profissional que favorece a oportunidade de um trabalho com alto grau de autonomia, como aponta Brien (1998). Os valores gerais de autotranscendência têm uma importância para a vida social ampla, mas no trabalho a busca por realização profissional e estabilidade exerce um papel mais importante para a adequação do indivíduo ao meio. Isso porque esses fatores ressaltam a importância do sucesso profissional baseado no êxito do trabalho e da independência e satisfação de necessidades materiais. Estes são elementos importantes para o desenvolvimento dos jovens na vida acadêmica e profissional.

\section{Conclusões}

O objetivo inicial desta pesquisa era investigar a influência dos valores laborais de pais, controlado o efeito do gênero, experiência de trabalho, gênero dos pais e valores dos colegas de curso, sobre os valores laborais dos estudantes universitários. A pesquisa realizada atingiu esse objetivo e os resultados apresentados deram apoio à hipótese inicial do estudo que previa a influência dos pais sobre os valores laborais de seus filhos. Observou-se que a transmissão ocorreu para os fatores de Realização Profissional e Estabilidade. Os resultados obtidos podem indicar que esses sejam os valores laborais privilegiados pelos pais no processo de transmissão. Ou seja, os valores laborais que podem fazer parte daqueles valores centrais em que os pais desejam a aquiescência dos filhos, enquanto os demais podem ser objeto de negociação. É possível que, para os pais de estudantes universitários, os valores de realização profissional sejam mais adaptativos. Entretanto, para outros grupos sociais com menor escolaridade e que visam profissões diferentes, valores de relações sociais podem ser mais importantes, como aponta a literatura sobre valores gerais (Phalet \& Schönpflug, 2001). Os valores de prestígio podem ser mais apropriados para indivíduos com ocupações que não são necessariamente acadêmicas como artistas, políticos ou mesmo entre profissões com maior reconhecimento social e que não foram alvo da pesquisa como a de médico e advogado. Estudos nesses grupos sociais são necessários para um conhecimento mais amplo dos mecanismos de transmissão dos valores laborais.

Se valores de realização profissional são mais adaptativos para carreiras que visam o ensino superior, seria interessante o desenvolvimento de ações que estimulassem estes valores em crianças e adolescentes para promover a continuidade dos estudos. Além disso, o estudo dos mecanismos de transmissão de valores em classes sociais mais baixas em que os pais não possuem elevado grau de escolaridade poderia lançar luz sobre a possibilidade de haver diferenças no mecanismo de transmissão dos valores entre pais com maior e menor escolaridade. Estudos nesta área apresentariam grande relevância social por possibilitarem o treinamento de pais na transmissão de valores, além da elaboração de programas sócio-instituicionais que possam incentivar a transmissão de valores adaptados ao mundo do trabalho.

\section{Limitações}

Um dos desafios da área de estudo sobre transmissão de valores refere-se à necessidade de estudos longitudinais sobre a formação e transmissão dos valores laborais. Seria interessante a realização de pesquisas que acompanhassem o desenvolvimento dos valores laborais ao longo do tempo. Provavelmente, essas pesquisas revelarão novas informações relevantes para a compreensão do fenômeno.

Como apontado na revisão de literatura, as pesquisas sobre transmissão de valores têm se concentrado na busca de similaridades entre indivíduos e poucos esforços tem sido feitos para compreender os mecanismos de internalização dos valores. O presente estudo não é uma exceção a esta crítica, entretanto ele apresenta dados interessantes sobre os agentes socializadores e cabe a pesquisas futuras investigar de que maneira é estabelecida a relação entre estes agentes e o indivíduo para proporcionar a internalização dos valores. Muito já se avançou sobre a transmissão entre pais e filhos no que se refere aos valores gerais. Estes estudos necessitam ser adaptados aos valores laborais e investigados nos diferentes contextos sociais brasileiros.

Como o objetivo era investigar os valores laborais de estudantes universitários, a amostra se restringiu a este público, mas as discussões levantadas sugerem a necessidade de investigar o processo de socialização em outras amostras, inclusive para identificar se os valores transmitidos de pais para filhos, observados na presente pesquisa, são escolhidos como mais adaptados para consecução da carreira acadêmica. Além disso, os resultados apontam para a necessidade de se investigar os processos de transmissão/internalização dos valores para compreender a origem dos valores laborais.

\section{Referências}

Biaggio, A.M.B. (1999). Universalismo versus relativismo no julgamento moral. Psicologia: Reflexão \& Crítica, 12, 5-20.

Borg, I. \& Braun, M. (1996). Work values in East and West Germany: different weights, but identical structures. Journal of Organizational Behavior, 17, 541-555.

Brien, A. (1998). Professional ethics and the culture of trust. Journal of Business Ethics, 17, 391-409.

Camino, C. (2003). Angela Biaggio (1940-2003): um percurso na história do desenvolvimento sócio-moral do Brasil. Psicologia: Reflexão \& Crítica, 16, V-VIII.

Camino, C., Camino, L., \& Moraes, R. (2003). Moralidade e socialização: estudo empíricos sobre práticas maternas de controle social e o julgamento moral. Psicologia: Reflexão छ Crítica, 16, 41-61.

Cavalli-Sforza, L.L. (1993). How are values transmitted? In M. Hechter, L. Nadel, \& R.E. Michod (Eds.), The origin of values (pp.305-317). New York: Aldine de Gruyter. 
Cheung, C.K. \& Scherling, S.A. (1999). Job satisfaction, work values, and sex differences in Taiwan's organizations. The Journal of Psychology, 133, 563-575.

Dawis, R.V. (1992). Vocational Interests, values, and preferences. In M.D. Dunette \& L.H. Hough (Eds.), Handbook of industrial and organizational psychology (Vol. 2). USA: Davies-Black.

Elizur, D. (1994). Gender and work values: a comparative analysis. The Journal of Social Psychology, 134, 201-212.

Elizur, D., Borg, I., Hunt, R., \& Beck, I. M. (1991). The structure of work values: a cross cultural comparison. Journal of Organizational Behavior, 12, 21-38.

Harpaz, I. (1990). The importance of work goals: An international perspective. Journal of International Business Studies, 21, 7593.

Iversen, R.R. \& Farber, N.B. (1996). Transmission of family values, work, and welfare among poor urban black women. Work and Occupations, 23, 437-460.

Judge, T.A. \& Bretz, R.D. (1992). Effects of work values on job choice decisions. Journal of Applied Psychology, 77, 261-271.

Manhardt, P.J. (1972). Job orientation of male and female college graduates in business. Personnel Psychology, 25, 361-368.

Meyer, J.P., Irving, G., \& Allen, N.J. (1998). Examination of the combined effects of work values and early work experinces on orgnaizational commitment. Journal of Organizational Behavior, 19, 29-59.

Michod, R.E. (1993). Biology and the origin of values. In M. Hechter, L. Nadel, \& R.E. Michod (Eds.), The origin of values (pp.261-271). New York: Aldine de Gruyter.

Mottaz, C. (1986). Gender differences in work satisfaction, workrelated rewards and values, and the determinants of work satisfaction. Human Relations, 39, 359-378.

Neil, C.C., \& Snizek, W.E. (1987). Work values, job characteristics, and gender. Sociological Perspectives, 30, 245-265.

Phalet, K. \& Schönpflug, U. (2001). Intergenerational transmission of collectivism and achievement values in two acculturation contexts: The case of Turkish families in Gemany and Turkish and Moroccan families in the Netherlands. Journal of CrossCultural Psychology, 32, 186-201.

Porto, J., \& Tamayo, A. (2003). Desenvolvimento e validação da escala de valores do trabalho - EVT. Psicologia Teoria e Pesquisa, 19, 145-152.

Roe, R.A., \& Ester, P. (1999). Values and work: Empirical findings and theoretical perspective. Applied Psychology: An International Review, 48, 1-21.

Rohan, M.J. (2000). A rose by any name? The values construct. Personality and Social Psychology Review, 4, 255-277.

Rohan, M.J., \& Zanna, M.P. (1996). Value transmission in families. In C. Seligman, J.M. Olson, \& M.P. Zanna (Eds.), Psychology of values: the Ontario Symposium (Vol. 8, pp.253-276). New Jersey: Lawrence Erlbaum.

Rokeach, M. (1973). The nature of human values. New York: The Free Press.
Ros, M., Schwartz, S.H., \& Surkiss, S. (1999). Basic individual values, work values, and the meaning of work. Applied Psychology: An International Review, 48, 49-71.

Sagie, A. \& Elizur, D. (1996). The structure of personal values: a conical representation of múltiple life areas. Journal of Organizational Behavior, 17, 573-586.

Sagie, A., Elizur, D., \& Koslowsky, M. (1996). Work values: a theoretical overview and a model of their effects. Journal of Organizational Behavior, 17, 503-514.

Schönpflug, U. (2001a). Introduction: Cultural transmission - A multidisciplinary research field. Journal of Cross-Cultural Psychology, 32, 131-134.

Schönpflug, U. (2001b). Intergenerational transmission of values: The role of transmission belts. Journal of Cross-Cultural Psychology, 32, 174-185.

Schwartz, S.H. (1992). Universals in the content and structure of values: Theoretical advances and empirical tests in 20 countries. In M.P. Zanna (Ed.), Advances in experimental social psychology (Vol. 24, pp.1-65). San Diego: Academic.

Schwartz, S.H. (1999). A theory of cultural values and some implications for work. Applied Psychology: An International Review, 48, 23-47.

Schwartz, S.H. \& Ros, M. (1995). Values in the west: A theoretical and empirical challenge to the individualism-collectivism cultural dimension. World Psychology, 1, 91-122.

Sidani, Y.M. \& Gardner, W. (2000). Work values among Lebanese workers. The Journal of Social Psychology, 140, 597-607.

Sverko, B. (1999). The work importance study: recent changes of values in Croatia. Applied Psychology: An International Review, 48, 89-102.

Tamayo, A. (1998). Gênero y prioridades axiológicas del adolescente. Acta Psiquiátrica y Psicológica América Latina, 44, 153-160.

Taris, R., \& Feij, J.A. (2001). Longitudinal examination of the relationship between supplies-values fit and work outcomes. Applied Psychology: An International Review, 50, 52-80.

Wijting, J.P., Arnold, C.R., \& Conrad, K.A. (1978). Generational differences in work values between parents and children and between boys and girls across grade levels 6, 9, 10 and 12 . Journal or Vocational Behavior, 12, 245-260.
Submissão: 11/03/2005 $1^{a}$ revisão: 24/06/2005 Última revisão: 20/10/2005 Aceite final: 08/11/2005 